\section{JNK targets p53 ubiquitination and degradation in nonstressed cells}

\author{
Serge Y. Fuchs, Victor Adler, \\ Thomas Buschmann, Zhimin Yin, Xiangwei Wu, \\ Stephen N. Jones, ${ }^{1}$ and Ze'ev Ronai ${ }^{2}$
}

The Ruttenberg Cancer Center, M ount Sinai School of Medicine, $\mathrm{N}$ ew Y ork, N ew York 10029 USA; ${ }^{1}$ University of M assachusetts M edical Center,

Worcester, M assachusetts 01655 USA

\begin{abstract}
In this study we elucidated the role of nonactive JNK in regulating p53 stability. The amount of p53-JNK complex was inversely correlated with p53 level. A peptide corresponding to the JNK binding site on p53 efficiently blocked ubiquitination of p53. Similarly, p53 lacking the JNK binding site exhibits a longer half-life than $p 53^{w t}$. Outcompeting JNK association with p53 increased the level of p53, whereas overexpression of a phosphoryla tion mutant form of JNK inhibited p53 accumulation. JNK-p53 and Mdm2-p53 complexes were preferentially found in $G_{0} / G_{1}$ and $S / G_{2} M$ phases of the cell cycle, respectively. Altogether, these data indicate that JNK is an Mdm2-independent regulator of p53 stability in nonstressed cells.
\end{abstract}

Received A pril 7, 1998; revised version accepted July 17, 1998.

The p53 tumor suppressor protein is a potent transcription factor (Kern et al. 1991; Zambetti et al. 1992; Friedlander et al. 1996) that is activated in response to various DN A-damaging agents (Fritsche et al. 1993; Hall et al. 1993; Zhan et al . 1993), leading to cell cycl earrest and/or apoptosis (Canman et al. 1995; Polyak et al. 1996). Disruption of this pathway occurs in a wide range of human cancers and is highly correlated with the tumorigenic phenotype (Harris 1996; Levine 1997). The key to the magnitude and duration of p53 activities lies in its stability (Maki et al. 1996; Brown and Pagano 1997). In normally growing cells, p53 half-life is limited to minutes, whereas cellular stress or exposure to DNA-damaging agents prolongs it to hours (M al tzman and Czyzyk 1984). Proteins known to alter p53 stability include HPV16-E6 (Huibregtse et al. 1991), WT-1 (Maheswaran et al . 1995), E1B/E4orf6 (Querido et al . 1997), SV40 T-antigen (Reihsaus et al. 1990; Tiemann et al. 1995), and M dm2 (Haupt et al. 1997; Kubbutat et al . 1997). Whereas association of SV40 T antigen, WT1, or E1B/E4orf6 with p53 increases its stability, the binding of E6 or M dm2 with p53 accelerates its degradation. To date, $\mathrm{Mdm} 2$ is the only cellular protein whose direct association with p53 results in its

[Key Words: JN K; p53; ubiquitination; degradation; Mdm2] ${ }^{2}$ Corresponding author.

E-MAIL zeev_ronai@smtplink.mssm.edu; FAX (212) 849-2446. ubiquitination and subsequent degradation (Haupt et al. 1997; Honda et al. 1997; Kubbutat et al. 1997; Fuchs et al. 1998a). The regulation of p53 stability has been associated with post-translational modifications, including phosphorylation on amino-terminal residues (Shieh et al. 1997; Siliciano et al. 1997).

In previous studies we found that Jun-N (amino)-terminal kinase (JNK) targets the ubiquitination and stability of its associated proteins, c-Jun (Fuchs et al. 1996), JunB, and ATF2 (Fuchs et al. 1997). JNK targeting for ubiquitination occurs in a phosphorylation-dependent manner as phosphorylated forms of c-Jun and ATF2 were found to be protected against JNK-targeted ubiquitination. Essential for JN K's ability to target the ubiquitination of ATF2, c-Jun, and JunB is its association with each of these proteins (Fuchs et al. 1996, 1997). Recent evidence for JNK association with p53 (Adler et al. 1997) provided the foundation for our hypothesis that JN K al so has a role in the regulation of p53 stability.

\section{Results and Discussion}

The association between JNK and p53 in vivo was first demonstrated via coimmunoprecipitations (Fig. 1a; Adler et al. 1997). JNK-p53 complex was preferentially found in nonstressed cells; after UV irradiation its concentration decreased immensely (Fig. 1a). Whereas $>30 \%$ of p53 is in complex with JN K 0.5 hr after UV irradiation, $2 \%$ of p53 is bound to JNK after 4-8 hr. The extent of JNK association with p53 is inversely correlated with p53 expression levels, suggesting that JN K could affect p53 stability in nonstressed cells.

Previous studies showed that JNK association with p53 requires amino acids 97-155 within the p53 central domain (Adler et al . 1997). A 20-amino aci d peptide spanning amino acids 97-116 (designated p7) was found capable of al tering p53 phosphorylation (Adler et al . 1997). To test the effect of $\mathrm{p7}$ on JNK association with p53, increasing concentrations of the $\mathrm{p} 7$ pepti de, or its control pepti de (c7), were added in vitro to purified forms of JNK and p53. As shown in Figure 1b, p7, but not c7, caused a dose-dependent inhibition of JNK association with p53 (Fig. 1b). Although able to inhibit the formation of the JNK-p53 complex, p7 would not dissociate the preformed JNK-p53 complex (Fig. 1b). When added to a solid-phase kinase reaction, p7 inhibited p53 phosphorylation by JNK (Fig. 1b, bottom).

To test the effect of JNK-p53 association on p53 ubiquitination in vivo, we utilized BALB/3T3/12.1 cells (Harvey and Levine 1991); these cells express normal levels of $\mathrm{Mdm2}$, which exhibited weak association with p53 ${ }^{\text {wt }}$ (not shown). Transfection of p7 or c7 cDNA to BALB/3T3/12.1 revealed that $p 7$ (but not $c 7$ ) inhibited the association of endogenous p53 with JNK (Fig. 1C). To determine the relationship between p53-JNK association and p53 ubiquitination, BALB/3T 3/12.1 cells were cotransfected with ${ }_{\text {his }} \mathrm{p} 53$ and HA-tagged ubiquitin. This approach allows one to follow the amount of the polyu- 


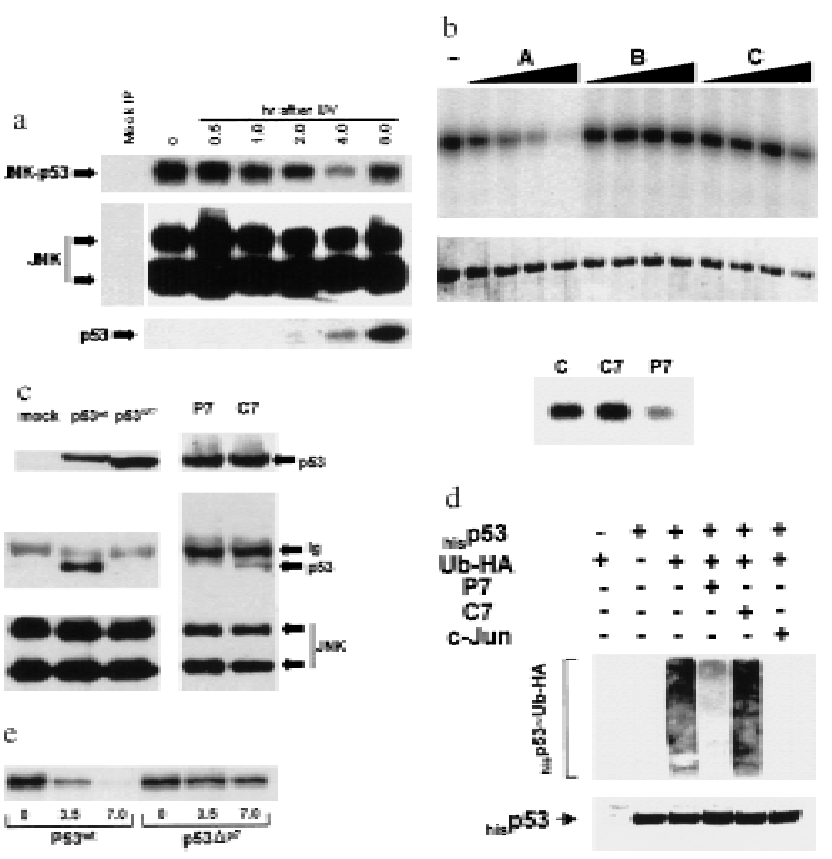

Figure 1. (a) In vivo association of JNK with p53 before and after UV irradiation. M ouse fibroblasts (BALB/3T3/12.1) were subjected to sham (C) or UV treatment, and proteins (4 mg) prepared at the time points indicated were immunopreci pitated with antibodies to JNK. Immunoprecipitated material (IP) was subjected to immunoblot (IB) using p53 antibodies (top) or antibodies to JNK (middle). (Bottom) The amount of p53 in wholecell extracts. (b) JNK binding to p53 is inhibited by p7. Binding of bacterially expressed his-tagged human p53 to a purified form of JNK (lane $\rightarrow$ was assessed in the presence of p7 (A), c7 peptide (B) at 1, 2, 4, or $8 \mu \mathrm{g}$, or when p7 was added after incubation of JNK with p53 (C). (Top) An immunoblot with JNK antibodies; (middle) a Ponceau S-stai ned membrane; (bottom) an autoradiograph of p53 phosphorylation by JN K in the presence of p7, c7, or no peptide (C). (c) Effect of p7 on JN K-p53 association in vivo. (Right) BALB/3T3/12.1 cells were transfected with cDNA of either p7 or $\mathrm{c7}$ (cloned in-frame with penetratin-HA sequence into pcDNA3). (Top) The level of p53 in whole-cell extracts. p53-JN K association was monitored via immunoprecipitation with antibodies to JNK before immunoblot with antibodies to p53 (middle). The same immunoblot was reprobed with antibodies to JNK (bottom). (Left) p53 null cells (10.1) were transfected with either $\mathrm{p} 53^{\mathrm{wt}}$ or $\mathrm{p} 53^{\Delta \mathrm{p} 7}$ constructs. Protein extracts prepared $36 \mathrm{hr}$ after transfection and $8 \mathrm{hr}$ after treatment with lactacystin $(5 \mu \mathrm{M})$ were processed as indicated above. (d) In vivo ubiquitination of p53 in BALB/3T 3/12.1 cells. CDN As of ${ }_{\text {his }}$ p53, ubiquitin-HA, and either $\mathrm{C7}, \mathrm{p7}$, or c-Jun were cotransfected into BALB/3T $3 / 12.1$ cells. p53 ubiquitination was monitored in immunblots performed on nickel resin-purified proteins. The upper part of the membranes (above $55 \mathrm{kD}$ ) was probed with antibodies to HA to identify any p53-associated tagged ubiquitin-HA; the lower part was analyzed using antibodies to p53. (e) In vivo stability of $\mathrm{p} 53^{\Delta \mathrm{p} 7}$. $\mathrm{p} 53^{\mathrm{wt}}$ or $\mathrm{p} 53^{\Delta \mathrm{p} 7}$ constructs were transfected into 10.1 p53 null cells that were metabolically labeled with $0.5 \mathrm{mCi} / \mathrm{ml}\left[{ }^{35} \mathrm{~S}\right]$ methionine for $10 \mathrm{~min}$ and chased with medium supplemented with $2 \mathrm{~mm}$ of unlabeled methionine. Proteins prepared at the indicated time points were immunopurified using PAb 421 antibodies and analyzed on SDSpolyacrylamide gels via autoradiography. biquitin chains formed on a substrate in vivo (Trei er et al. 1994). This assay reveal ed that $p 7$ (but not c7) transfection markedly decreased p53 ubiquitination (Fig. 1d).

Further support for JN K's role in regulating p53 stability comes from the use of a p53 construct whose JNKbinding domain was del eted ( $\left.p 53^{\Delta \mathrm{p} 7}\right)$. This mutant was not found in the complex with JNK as assayed by coimmunoprecipitation (Fig. 1c). Lack of JNK association with $\mathrm{p} 53^{\Delta \mathrm{p} 7}$ in $10.1 \mathrm{p} 53$ null cells coincided with prolonged half-life of $\mathrm{p} 53^{\mathrm{sp} 7}$ as compared with the p53 (Fig. 1e). The importance of the 100-150 amino acid region for p53 stability was demonstrated previously as its fusion with a long-lived protein, ornithine decarboxylase, reduced stability of the chimeric protein ( $\mathrm{Li}$ and C offino 1996).

Because JN K associati on with its substrate is a prerequisite for targeting ubiquitination of c-Jun, JunB, and ATF2 (Fuchs et al. 1996, 1997), we determined whether outcompeting JN K with another substrate, c-Jun, would affect p53 stability. Transfecting increasing amounts of c-Jun led to a dose-dependent increase in p53 level (Fig. $2 \mathrm{a}, \mathrm{I})$. These changes were not observed in cells treated with the proteasome inhibitor lactacystin, suggesting that c-Jun does affect p53 stability (Fig. 2a, II). Importantly, transfection of amino-terminal Jun ${ }^{1-110}$ (which lacks DN A-binding capacity) or amino-terminal JN K ${ }^{1-202}$ increased p53 level (Fig. 2a, III) and decreased the amount of p53 that could be coimmunoprecipitated with JNK (Fig. 2a, III). Similar to its effect in mouse fibroblasts, JN K $^{1-202}$ expression led to accumulation of endogenous p53 ${ }^{\text {wt }}$ in human melanoma and breast cancer cells (Fig. 2b). Whereas cotransfection of c-Jun inhibited in vivo ubiquitination of p53 (Fig. 1d), pulse-chase label ing with ${ }^{35}$ S]methionine revealed that the p53 half-life in cells that express high levels of c-Jun was extended to $>8 \mathrm{hr}$ (Fig. 2a, IV). Cotransfection of c-Jun with p53 ${ }^{\Delta p 7}$ did not elevate the expression of this p53 form (Fig. 3a), which lacks JN K-binding sites, suggesting that overexpression of c-Jun stabilizes p53 through a JN K-dependent mechanism. Together, these data suggest that c-Jun affects p53 stability by squelching JNK.

The effect of $\mathrm{Mdm} 2$ on p53 degradation was demonstrated previously via overexpression of $\mathrm{Mdm} 2$ (Haupt et al. 1997; Kubbutat et al. 1997). Unlike M dm2 expression, JNK is constitutively expressed at high levels, because of which further increase in JN K expression is expected to have a limited effect on the half-life of JN K-associated proteins. To overcome this problem, we have tested the effect of inactive mutant JN K2 construct (T 183A, Y 185F; Galcheva-Gargova et al. 1994) on elevated levels of p53. The mutant form of JN K2 $2^{183,185}$ has attenuated the increase in p53 level mediated by p53 overexpression with or without Jun ${ }^{1-110}$ in BALB/3T 3/12.1 mouse fibrobl asts (Fig. 2C). Moreover, expression of mutant JNK2 ${ }^{183,185}$ prevented taxol-induced accumulation of p53 in MCF7 breast cancer cells (Fig. 2d). These data suggest that phosphorylation-deficient JNK is capable of targeting p53 degradation. The kinase activity of JNK was also found to be dispensable for targeting ubiquitination of c-Jun (Fuchs et al. 1996). 


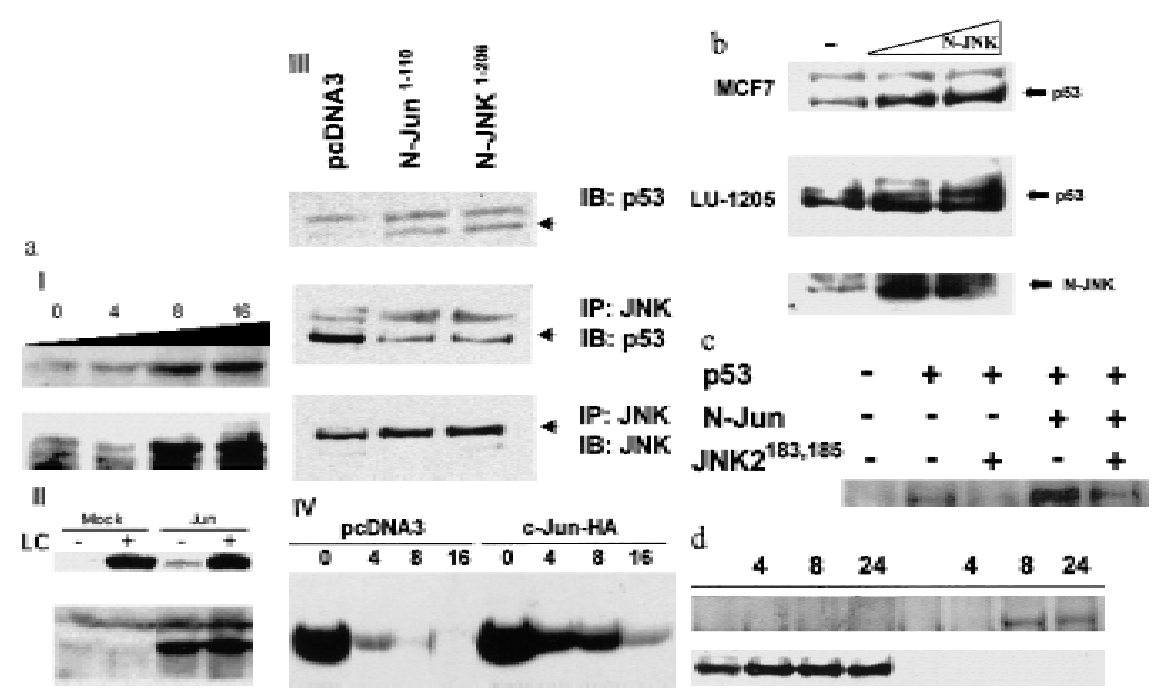

Figure 2. (a) Overexpression of c-Jun stabilizes expression of p53. (I) BALB/3T3/12.1 cells were transfected with increasing amounts $(\mu \mathrm{g})$ of HA-tagged c-Jun (Treier et al. 1994) as indicated. The total amount of DN A in all transfections was equal ized. Wholecell extracts prepared $24 \mathrm{hr}$ after transfection were analyzed via immunobl ot using antibodies to p53 (top) and antibodies to HA (bottom, upper band). (II) BALB/ 3T $3 / 12.1$ cells were transfected with HA-tagged c-Jun $(8 \mu \mathrm{g})$ and cells treated with $5 \mu \mathrm{M}$ lactacystin (LC) for $8 \mathrm{hr}$ as indicated. Extracts prepared $24 \mathrm{hr}$ after transfection were analyzed as in I. (III) A mino-terminal Jun (N-Jun ${ }^{1-110}$ ) or amino-terminal JNK (N-JNK K $\left.{ }^{1-202}\right)$ was transfected into BALB/3T 3/12.1 cells, and proteins prepared from cells $24 \mathrm{hr}$ after transfection were analyzed via immunoblot to determine p53 level (top). The complex between JNK and p53 was measured via immunoblots with antibodies to p53 on material that was first immunoprecipitated (from $800 \mu \mathrm{g}$ of the same extracts) with antibodies to JNK (middle). (Bottom) Expression level of full-length JNK. Transfection with pcDN A3 was used as control. (IV) Half-life of p53 increases in c-Jun-overexpressing cells. pCDNA3 or c-Jun-HA was transfected into BALB/3T 3/12.1 cells that were metabolically label ed with [ $\left.{ }^{35} \mathrm{~S}\right] \mathrm{methionine}$ for $10 \mathrm{~min}$ and chased with $2 \mathrm{~mm}$ unlabel ed methionine for the indicated time periods. Endogenous p53 was immunopurified from the extracts prepared at the indicated time points of methionine chase. Immunoprecipitates were separated by SDS-PAGE and analyzed via autoradiography. (b) Amino-terminal JNK $\left(\mathrm{N}-\mathrm{N} \mathrm{K} \mathrm{K}^{1-206}\right.$ ) was transfected (3.5 or $7 \mu \mathrm{g}$, lanes 2 and 3, respectively) into breast cancer (M CF7)- or human melanoma (Lu-1205)-derived cell lines. p53 level was determined via immunoblot with antibodies pAb 421. (Bottom) Expression of HA-tagged N-JN K ${ }^{1-206}$, which was identified with the aid of HA antibodies. (c) Rat p53, human Flag-tagged JN K2 ${ }^{183,185}$, and Jun ${ }^{1-110}$ were expressed in BALB/3T3/12.1 cells as indicated. p53 was immunopreci pitated with pAb 421 and anal yzed by immunobl otting with anti-p53 polyclonal antibody. (d) MCF7 cells were transfected with Flag-tagged JN K2 ${ }^{183,185}$ (left) or empty pcDN A 3 vector (right) and $24 \mathrm{hr}$ later treated with taxol $(1 \mu \mathrm{M})$. Protein extracts, prepared 4, 8, and $24 \mathrm{hr}$ after taxol addition, were analyzed by immunoblotting with anti-p53 polyclonal antibody (top) or M2 anti-Flag monoclonal antibody (IBI Kodak; bottom).

To investigate the relationship between $\mathrm{Mdm} 2$ and JNK targeting of p53 degradation, the level of p53 mutants that cannot associate with $\mathrm{Mdm} 2$ ( $\mathrm{p} 53^{22,23}$; Lin et al. 1994) or JN K (p53 ${ }^{\Delta \mathrm{p} 7}$; Fig. 1c) was monitored in cells that had been transfected with either $\mathrm{c}$-Jun (to squelch JNK) or Mdm2. Although cotransfection of $\mathrm{Mdm} 2 \mathrm{did}$ not affect the level of p5322,23 (Fig. 3a; Kubbutat et al. 1997), cotransfection of c-Jun increased the level of the p5322,23 form (Fig. 3a), indicating that the stability of p53 that no longer responds to $\mathrm{Mdm} 2$ can still be affected by JNK. C-Jun had similar effects on the expression level of $\mathrm{p5}^{\mathrm{wt}}$. Cotransfection of $\mathrm{Mdm} 2$ with $\mathrm{p}^{\mathrm{w}} 3^{\Delta \mathrm{p} 7}$ decreased the level of this p53 mutant, which is not affected by
c-Jun overexpression. Both c-Jun and $\mathrm{Mdm} 2$ affected the level of cotransfected p53 ${ }^{\text {wt }}$ (Fig. 3a). These observations confirm that $\mathrm{Mdm} 2$ and JNK independently regulate $\mathrm{p} 53$ stability.

Because M dm2 was found to associate with p53 and mediate its degradation, we explored the possible interplay between $\mathrm{Mdm} 2$ and JNK. We monitored Mdm2-p53 and JN K-p53 complexes at different phases of the cell cycle in Swiss $3 T 3$ cells that were synchronized by serum starvation. Analysis at $0,8,20$, and $24 \mathrm{hr}$ after growth release (representing $\mathrm{G}_{0}, \mathrm{G}_{1}$, $\mathrm{S}$, and $\mathrm{G}_{2} / \mathrm{M}$ phases of the cell cycle, respectively) revealed that JN K-p53 complexes were preferentially found in $G_{0} / G_{1}$, whereas $M d m 2-p 53$ complexes were primarily found in $\mathrm{S}$ and $\mathrm{G}_{2} / \mathrm{M}$ phases of the cell cycle (Fig. $3 b)$.

Further support for the role of JNK in targeting p53 ubiquitination was obtained through the use of a solidphase in vitro ubiquitination assay. In this assay, beads-bound human ${ }_{\text {his }}$ p53 was incubated with targeting proteins, followed by extensive washing and subsequent ubiquitination using reticulocyte lysates that were immunodepleted of JNK and M dm2. In this system, adding exogenously purified JNK as the targeting molecule re sulted in increased ubiquitination of p53 as indicated by the smear at the top of the gel (Fig. 4). JN K's ability to target p53 ubiquitination was inhibited when $\mathrm{p7}$, but not $\mathrm{c7}$, was added at the targeting step of our in vitro ubiquitination assay. P7's ability to block JNK targeting of p53 ubiquitination suggests that its effects in vivo (Fig. 1c,d) are primarily mediated through interference with JNK interaction with the endogenous $p 7$ domain on p53. Wild-type Mdm2, added as exogenously purified protein, efficiently targeted p53 ubiquitination, whereas mutant $\mathrm{Mdm} 2$, which cannot bind p53, failed to mediate this targeting (Fig. 4b). In contrast to its inhibitory effects on JNK, p7 did not inhibit M dm2 targeting of $p 53$ ubiquitination. Efficient targeting of p53 ubiquitination was also achieved using protein extracts from M dm2/p53 null cells (Jones et al. 1996). However, targeting $\mathrm{p} 53$ ubiquitination by $\mathrm{M} \mathrm{dm2/p53} \mathrm{null} \mathrm{cell} \mathrm{pro-}$ teins could be inhibited by adding p7. Similarly, immunodepleting JNK from $\mathrm{M} \mathrm{dm2/p53} \mathrm{null} \mathrm{cell} \mathrm{extracts} \mathrm{sig-}$ nificantly reduced p53-targeted ubiquitination. That JNK immunodepletion did not completely abolish p53 ubiquitination suggests that other p53 targeting mol- 


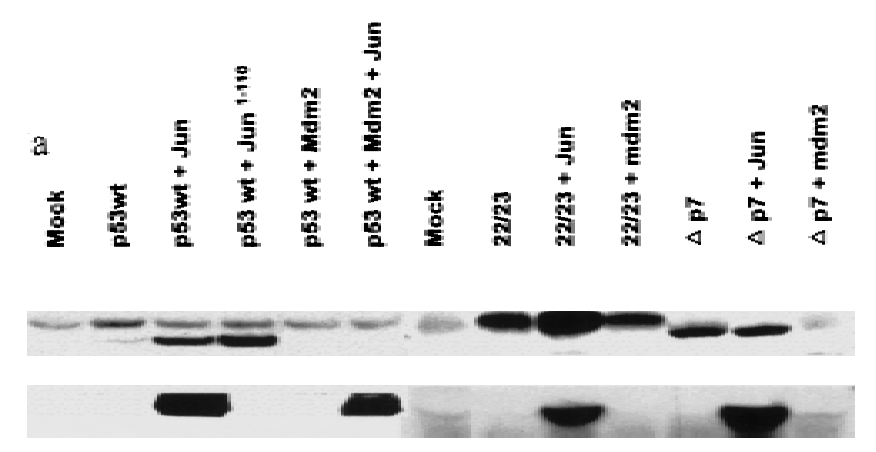

b
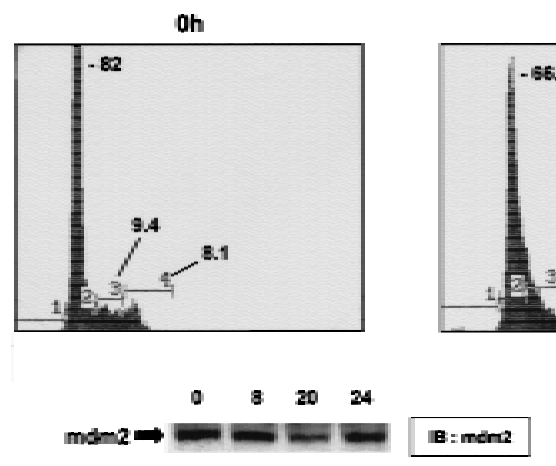

8h

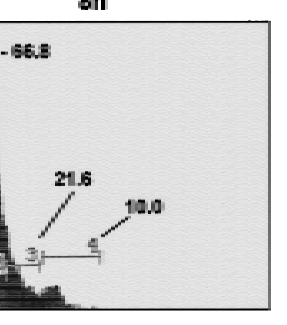

0

mdm2 $\Rightarrow$

F53
$20 \mathrm{~h}$

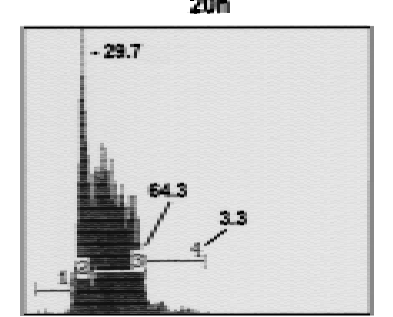

24

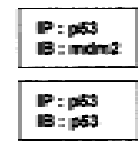

$24 h$

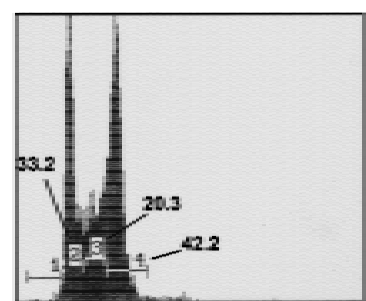

- $\quad 2024$
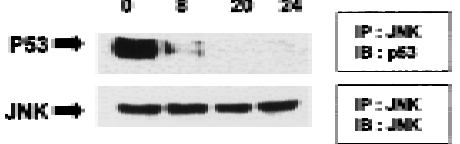

Figure 3. (a) Effect of $M d m 2$ and c-Jun on levels of $p 53^{22,23}$ and $p 53^{\Delta p 7}$. p53 (of the forms indicated) was cotransfected into p53 null (10.1) cells together with pCMV-M dm2, pCMV-Jun-HA, or pCMV-Jun ${ }^{1-110}$ as indicated. p53 proteins were immunopurified using pAb 421 and analyzed via immunoblot probed with the p53 polyclonal antibody. (Bottom) Immunoblots controlling for the amount of Jun-HA expressed. (b) Analysis of JNK and M dm2 association with p53 at different phases of the cell cycle. (Top) Swiss 3 T 3 cells were synchronized at the $G_{0}$ phase. Cells were then fed $10 \%$ serum, and samples were collected after $0,8,20$, and 24 hr representing the majority of cells at the $G_{0}, G_{1}, S$, and $G_{2} / M$ phases, respectively. (Bottom) Swiss 3T 3 cells maintained under the same conditions also served as a source for analysis of p53 association with JNK or M dm2.

ecules may exist in these JNK-depleted Mdm2 null extracts. Supplementing JNK-immunodepleted extracts with purified JNK restored targeting p53 for ubiquitination.

To determine the degree of $\mathrm{p} 53$ ubiquitination mediated by JNK, we used in vitro-translated $\left[{ }^{35}\right.$ S]methioninelabeled p53 as the substrate. Quantifying the polyubiquitinated form of p53 revealed that within $30 \mathrm{~min}$, $\sim 15 \%$ of p53 was targeted for ubiquitination by JN K (data not shown). Targeting of p53 ubiquitination can al so be mediated by in vitro-translated wild-type or phosphorylation mutant (JNK2 ${ }^{183,185}$ ) forms (data not shown), suggesting that JNK does not require its kinase activities to target p53 ubiquitination, as was observed previously with ATF2 and C-Jun (Fuchs et al. 1996, 1997). Similar targeting occurred when bacul ovirus-produced human or murine p53 was used as the substrate for these reactions (not shown). These data suggest that via its association, JNK directly targets p53 ubiquitination.

In sum, this study demonstrates that in nonstressed normally growing cells, p53 ubiquitination and degradation are al so mediated by JNK. In both $\mathrm{Mdm} 2 / \mathrm{p} 53$ null cells and BALB/3T 3/12.1 cells, JNK appears to be the principal regulator of p53 ubiquitination. Our data also suggest that $\mathrm{Mdm} 2$ and JN K represent two independent pathways for targeting p53 stability. The fact that $\mathrm{Mdm} 2-\mathrm{p} 53$ complexes were found at $\mathrm{S}$ and $\mathrm{G}_{2} / \mathrm{M}$ phases of the cell cycle, but JN K-p53 complexes were in $\mathrm{G}_{0} / \mathrm{G}_{1}$ phases, suggests that through their targeting of p53 stability in nonstressed cells, $\mathrm{Mdm} 2$ and JNK may regulate different cellular functions of p53 during normal cell growth. Our data do not preclude the existence of other targeting molecules, as immunodepletion of JNK from M dm2 null cell lysates did not completely abolish p53 targeting for in vitro ubiquitination.

In line with our previous studies, stress-mediated JNK activation inversely correlates with targeting of its associated proteins, as shown here for p53. JNK activation via MEKK1 results in p53 phosphorylation, inhibition of $\mathrm{Mdm} 2$ association, and p53 ubiquitination as reflected by a prolonged p53 half-life (Fuchs et al. 1998b). Yet be cause JN K from UV-treated cells can still associate with recombinant $\mathrm{p} 53$ in vitro, it is possible that in vivo p53 phosphorylation in response to stress requires multiple stress kinases, which mediate sufficient changes to p53 conformation to result in $\mathrm{p} 53$ dissociation from its targeting molecules.

The emerging model supported by our current data 


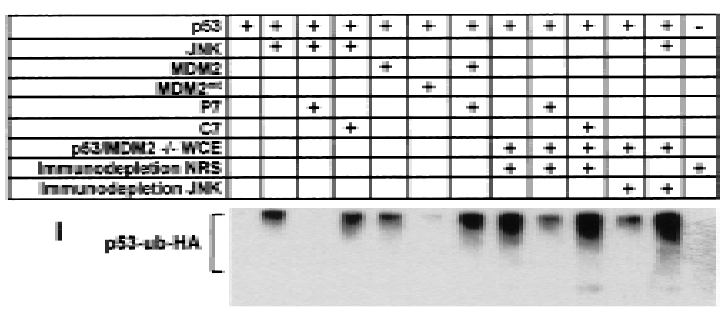

II

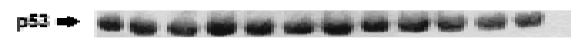

Figure 4. JNK and extracts from $M d m 2 / p 53$ null cells target p53 ubiquitination in vitro. Targeting ubiquitination of ${ }_{\text {his }} \mathrm{p} 53$ in vitro was performed using either purified components (JNK; M dm2) or whole-cell extracts (WCE) from M dm2/p53 null cells (Jones et al. 1996). Where indicated, whole cell extracts were immunodepleted with antibodies to JNK or with naive rabbit serum (N RS). Peptides (p7 or c7) were added (40 $\mu$ m per reaction) in parallel to addition of the respective targeting protein(s), as indicated. In all cases ${ }_{\text {his }}$ p53-associated proteins were subjected to extensive washes before proceeding to the ubiquitination step, which utilizes reticul ocyte lysates in the presence of $\mathrm{Ub}$ HA (Fuchs et al. 1997). (I) Immunobl ot using antibodies to HA. Polyubiquitinated p53 is marked on the left. (II) A Ponceau S stain of the same membrane to verify that equal amounts of p53 were used throughout the reaction.

suggests that p53 stability is affected by JNK independently of $\mathrm{Mdm} 2$ in a cell cycle-dependent manner. In this model, prolonged half-life, which is characteristic of mutant forms of p53, could be attributed to lack of p53 association with one or both targeting molecules. JN K is likely to be among the growing number of adapter molecules that participate in the formation of the E3 ubiquitin/ligase compl ex. Such adapters were shown to have key roles in substrate recognition and targeting ubiquitination of yeast CDK inhibitor protein Sicl (Feldman et al. 1997; Skowyra et al. 1997). A similar mechanism was described for HPV-mediated p53 degradation through the recruiting of E6-AP ubiquitin ligase with the aid of the E6 viral protein (Huibregtse et al. 1991). As a targeting molecule that mediates the stability of the oncogene, c-Jun, and the tumor suppressor p53, JN K emerges as a key regulator of cell growth in normally growing cells.

\section{Materials and methods}

\section{Preparation of JNK and Mdm2}

JNK was purified from $600 \mathrm{mg}$ of protein extract prepared from UVirradiated $\left(60 \mathrm{~J} / \mathrm{m}^{2}\right)$ BALB/3T3 cells as described (Adler et al. 1995). A purified form of JNK ( $54 \mathrm{kD}$, as reveal ed by immunoblotting) was used for in vitro ubi quitination assays $(\sim 1 \mu \mathrm{g} /$ assay). $\mathrm{M} \mathrm{dm} 2$ was prepared from Sfg cells infected with baculovirus-expressing human $\mathrm{M} \mathrm{dm} 2 \mathrm{cDN} A$ in either wild-type or mutant ( $\Delta 1-150)$ forms and purified as described previously (Chen et al. 1996). The purity of M dm2 and JNK was confirmed as single bands seen on silver-stained gels.

Immunoprecipitations/immunodepletions

JNK was immunodepleted from reticulocyte lysates and protein extracts of $\mathrm{Mdm} 2 / \mathrm{p} 53$ null cells by incubating $700 \mu \mathrm{g}$ of proteins with $1 \mu \mathrm{g}$ of antibody to JNK (C-17; Santa Cruz) for $16 \mathrm{hr}$ at $4^{\circ} \mathrm{C}$. Protein A/G beads were added to this mixture for $2 \mathrm{hr}$ at $4^{\circ} \mathrm{C}$, followed by quick centrifugation. Supernatants were used as JN K-depleted proteins. Monoclonal antibodies were used for immunoprecipitation (clone 333, PharM ingen) and for immunodepletion of JNK (clone 666) as described (Fuchs et al. 1997).
Construction of expression vectors

To express peptides in vivo, oligonucleotides bearing the sequence of $p 7$ (VPSQKTYHGSYGFRLGFLHSG) or c7 control peptide (SPPVVPSQSKSTSYGQGYRF) were cloned, respectively, in-frame into pCDNA3 that carries the penetratin sequence (RQIKIWFQN RRM KWKK), followed by the sequence encoding the HA tag (Y PYDVPDYASL). Using antibodies to HA enables detection of these fusion peptides (not shown). To generate a p53 expression vector that is histidine-tagged, CDNA of rat p53 was cloned into a pCDNA3 vector by PCR using $5^{\prime}$ primer that encodes amino-terminal 6 xhis, thus generating the ${ }_{\text {his }} \mathrm{p} 53$ fusion protein. To generate $\mathrm{p} 53$ whose $\mathrm{p} 7$ sequence has been deleted, the rat CDNA of p53 ( $\mathrm{pCMV}{ }_{-}$his $\mathrm{p} 53$ ) was deleted from amino acids 95-114 (corresponding to amino acids 97-116 of human p53, which constitute the p7 domain) using site-directed mutagenesis (Quick Change, Stratagene), resulting in the $\mathrm{p} 53^{\Delta \mathrm{p} 7}$ construct. Amino-terminal JNK (amino acids 1-202) and amino-terminal c-Jun (amino acids 1-110) constructs were cloned by PCR into PCDNA3. The integrity and expression of all constructs were verified on the basis of sequencing and immunoblots.

In vitro ubiquitination assay and transfection

The in vitro ubiquitination assay was performed as described (Fuchs et al . 1997). Transfection was performed via lipofection (DOTAP) into subconfluent $60-\mathrm{mm}$ plates. In all cases, equal amounts of DNA were transfected (by adjusting the concentrations of respective constructs with empty mammalian expression vector).

\section{Acknowledgments}

We thank Bin Xie for technical assistance, Fred Friedman for peptide synthesis, Z.Q. Pan for Sf-9 cells, T. Soussi for p53 construct, D. Bohmann for ubiquitin-HA and Jun-HA vectors, Roger Davis and Michael Karin for JNK constructs, James Manfredi for the Taxol reagent, Craig Monnel of PharMingen for the JNK antibodies, and Arnold Levine for $\mathrm{Mdm} 2$ reagents. We also thank Stuart Aaronson, Victor Fried, and Ed Johnson for critically reading the manuscript. These studies were supported in part by National Cancer Institute grants CA59908 and CA78419 to Z.R.

The publication costs of this article were defrayed in part by payment of page charges. This article must therefore be hereby marked 'advertisement' in accordance with 18 USC section 1734 solely to indicate this fact.

\section{References}

Adler, V., M.R. Pincus, P.W. Brandt-Rauf, and Z. Ronai. 1995. Complexes of p21RAS with JUN N-terminal kinase and JUN proteins. Proc. Natl. Acad. Sci. 92: 10585-10589.

Adler, V., M.R. Pincus, T. Minamoto, S. Fuchs, M.J. Bluth, P.W. BrandtRauf, F.K. Friedman, R.C. Robinson, J.M. Chen, X.W. Wang, C.C. Harris, and Z. Ronai. 1997. Conformation-dependent phosphorylation of p53. Proc. Natl. Acad. Sci. 94: 1686-1691.

Brown, J.P. and M. Pagano. 1997. p53 stability. Biochem. Biophys. Acta 1332: 1-6.

Canman, C.E., T.M. Gilmer, S.B. Coutts, and M.B. Kastan. 1995. Growth factor modulation of p53-mediated growth arrest versus apoptosis. Genes \& Dev. 9: 600-611.

Chen, J., X. Wu, J. Lin, and A.J. Levine. 1996. Mdm-2 inhibits the G1 arrest and apoptosis functions of the p53 tumor suppressor protein. Mol. Cell. Biol. 16: 2445-2452.

Feldman, R.M.R., C.C. Correl, K.B. Kaplan, and R.J. Deshaies. 1997. A complex of Cdc4p, Skplp, and Cdc53p/cullin catalyzes ubiquitination of the phosphorylated CDK inhibitor Siclp. Cell 91: 221-230.

Friedlander, P., Y. Legros, T. Soussi, and C. Prives. 1996. Regulation of mutant p53 temperature-sensitive DNA binding. J. Biol Chem. 271: 25468-25478.

Fritsche, M., C. Haessler, and G. Brandner. 1993. Induction of cellular p53 accumulation of the tumor-suppressor protein by DNA-damaging agents. O ncogene 8: 307-318.

Fuchs, S.Y., L. Dolan, R.J. Davis, and Z. Ronai. 1996. Phosphorylationdependent targeting of c-Jun ubiquitination by Jun N-kinase. Oncogene 13: 1531-1535. 
Fuchs, S.Y., B. Xie, V. Adler, V.A. Fried, R.J. Davis, and Z. Ronai. 1997. C-Jun $\mathrm{NH}$ 2-terminal kinases target the ubiquitination of their associated transcription factors. J. Biol. Chem. 272: 32163-32168.

Fuchs, S.Y., V. Adler, T. Buschmann, X. Wu, and Z. Ronai. 1998a. M dm2 association with p53 targets its ubiquitination. Oncogene (in press).

Fuchs, S.Y., V. Adler, M.R. Pincus, and Z. Ronai. 1998b. MEKK1/JNK signal ing stabilizes and activates p53. Proc. Natl. Acad. Sci. (in press).

Galcheva-Gargova, Z., B. Derijard, I.-H. Wu, and R.J. Davis. 1994. An osmosensing signal transduction pathway in mammalian cells. Science 265: 806-808.

Hall, P.A., P.H. McKee, H.P. Menage, R. Dover, and D.P. Lane. 1993. High levels of p53 protein in UV-irradiated normal human skin. Oncogene 8: 203-207.

Harris, C.C. 1996. Structure and function of the p53 tumor suppressor gene: Clues for rational cancer therapeutic strategies. J. Natl. Cancer Inst. 88: 1442-1455.

Harvey, D.M . and A.J. Levine. 1991. P53 alteration is a common event in the spontaneous immortalization of primary BALB/c murine embryo fibroblasts. Genes \& Dev. 5: 2375-2385.

Haupt, Y., R. Maya, A. Kazaz, and M. Oren. 1997. Mdm2 promotes the rapid degradation of p53. Nature 387: 296-298.

Honda, R., H. Tanaka, and H. Yasuda. 1997. Oncoprotein MDM2 is a ubiquitin ligase E3 for tumor suppressor p53. FEBS Lett. 420: 25-27.

Huibregtse, J.M., M. Scheffner, and P.M. Howley. 1991. A cellular protein mediates association of p53 with the E6 oncoprotein of human papillomavirus types 16 or 18. EMBO J. 10: 4129-4135.

Jones, S.N . A.T. Sands, A.R. Hancock, H. Vogel, L.A. Douchouer, S.P. Linke, G.M. Wahl, and A. Bradley. 1996. The tumorigenic potential and cell growth characteristics of p53-deficient cells are equival ent in the presence or absence of M dm2. Proc. Natl. Acad. Sci. 93: 1410614111.

Kern, S.E., K.W. Kinzler, A. Bruskin, D. Jarosz, P. Friedman, C. Prives, and B. Vogelstein. 1991. Identification of p53 as sequence-specific DN A-binding protein. Science 252: 1708-1711.

Kubbutat, M.H.G., S.N. Jones, and K.H. Vousden. 1997. Regulation of p53 stability by $\mathrm{Mdm2}$. Nature 387: 299-302.

Levine, A. 1997. P53, the cellular gatekeeper for growth and division. Cell 88: 323-331.

$\mathrm{Li}, \mathrm{Z}$. and P. Coffino. 1996. Identification of a region of p53 that confers liability. J. Biol. Chem. 271: 4447-4451.

Lin, J., J. Chen, B. Elenbaas, and A.J. Levine. 1994. Several hydrophobic amino acids in the p53 amino terminal domain are required for transcriptional activation, binding to $\mathrm{mdm} 2$ and the adenovirus $5 \mathrm{E} 1 \mathrm{~B}$ 55kd protein. Genes \& Dev. 8: 1235-1246.

Maheswaran, S., C. Engl ert, P. Bennett, G. Heinrich, and D.A. Haber. 1995. The WT 1 product stabilizes p53 and inhibits p53-mediated apoptosis. Genes \& Dev. 9: 2143-2156.

Maki, C.G., J.M. Huibregtse, and P.M. Howley. 1996. In vivo ubiquitination and proteasome-mediated degradation of p53. Cancer Res. 56: 2649-2654.

Maltzman, W. and L. Czyzyk. 1984. UV irradiation stimulate levels of p53 cellular tumor antigen in nontransformed mouse cells. Mol. Cell. Biol. 4: 1689-1694.

Polyak, K., T. Waldman, C. He, K.W. Kinzler, and B. Vogelstein. 1996. Genetic determinants of p53-induced apoptosis and growth arrest. Genes \& Dev. 10: 1945-1952.

Querido, E., R.C. Marellus, A. Lai, R. Charbonneau, J.G. Teodoro, G. Ketner, and P.E. Branton. 1997. Regulation of p53 levels by the E1B 55-kilodal ton protein and E4orf6 in adenovirus-infected cells. J. Virol . 71: 3788-3798.

Reihsaus, E., M. Kohler, S. Kraiss, M. Oren, and M. Montenarh. 1990. Regulation of the level of the oncoprotein p53 in non-transformed and transformed cells. Oncogene 5: 137-145.

Shieh, S.Y., M. Ikeda, Y. Taya, and C. Prives. 1997. DNA damaged induced phosphorylation of p53 alleviates inhibition by $\mathrm{Mdm} 2$. Cell 91: 325-334.

Siliciano, J.D., C.E. Canman, Y. Taya, K. Sakaguchi, E. A ppella, and M.B. Kastan. 1997. DNA damage induces phosphorylation of the amino terminus of p53. Genes \& Dev. 11: 3471-3481.

Skowyra, D., K.L. Craig, M. Tyers, S.J. Elledge, and J.W. Harper. 1997. F-box proteins are receptors that recruit phosphorylated substrates to the SCF ubiquitin-ligase complex. Cell 91: 209-219.

Tiemann, F., J. Zerrah, and W. Deppert. 1995. Cooperation of simian virus 40 large and small $\mathrm{T}$ antigens in metabolic stabilization of tumor suppressor p53 during cellular transformation. J. Virol. 69: 61156121.

Treier, M., L. Staszewski, and D. Bohmann. 1994. Ubiquitin-dependent c-jun degradation in vivo is mediated by the $\delta$ domain. Cell 78: 787798.

Zambetti, G.P., J. Bargonetti, K. Walker, C. Prives, and A.J. Levine. 1992. Wild-type p53 mediates positive regulation of gene expression through a specific DN A sequence element. Genes \& Dev. 6: 11431152.

Zhan, Q., F. Carrier, and A.J. Fornace. 1993. Induction of cellular p53 activity by DNA-damaging agents and growth arrest. Mol. Cell. Biol 13: 4242-4250. 


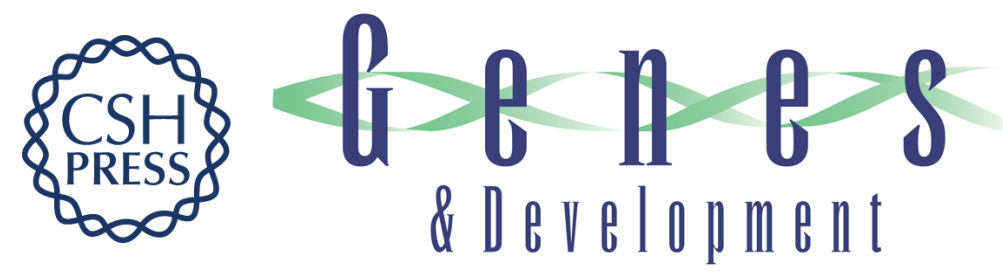

\section{JNK targets p53 ubiquitination and degradation in nonstressed cells}

Serge Y. Fuchs, Victor Adler, Thomas Buschmann, et al.

Genes Dev. 1998, 12:

Access the most recent version at doi:10.1101/gad.12.17.2658

References This article cites 36 articles, 21 of which can be accessed free at: http://genesdev.cshlp.org/content/12/17/2658.full.html\#ref-list-1

License

Email Alerting Receive free email alerts when new articles cite this article - sign up in the box at the top Service right corner of the article or click here.

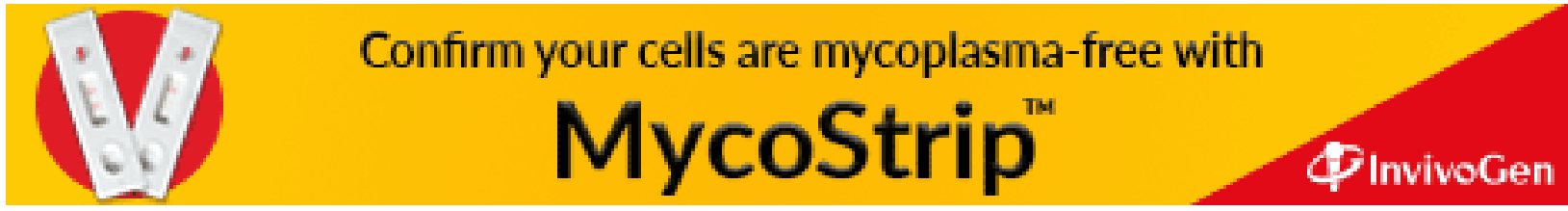

